\section{Gender vs career aspirations}

The influence of genders on career aspirations of University of Birmingham dental students and junior trainees in the West Midlands, United Kingdom. Br Dent J 2020; 228: 944-937. https://doi. org/10.1038/s41415-020-1704-6.

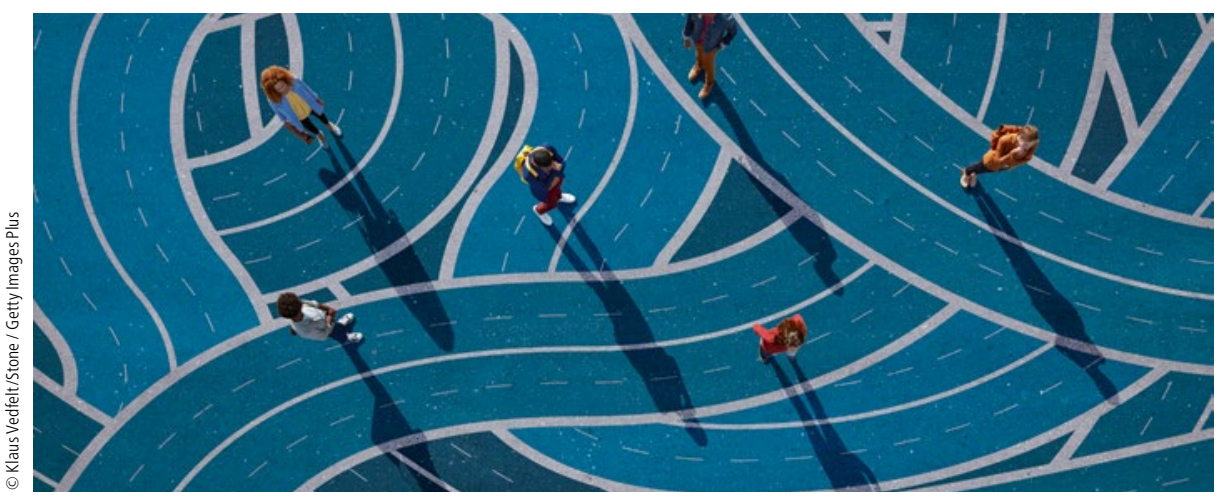

It is widely acknowledged that there are increased numbers of females entering the dental workforce, both within the UK and worldwide. These increased numbers are recognised amongst undergraduate dental students and GDC registrants. Literature provides evidence as to why females are likely to undertake a career in dentistry, in addition to the multifaceted nature of career specialisation, which may not be conducive towards female success within the workforce.

The study investigated how gender differences can affect career aspirations and working patterns amongst 189 undergraduate dental students from Years 2-4 at the University of Birmingham, and 24 dental core trainees (DCTs) within the West Midlands region. In July 2017, questionnaires were delivered to participants and subsequently analysed. The questionnaire explored career choice, career plans, NHS vs private practice, and anticipated work patterns. Out of the respondents, $64.3 \%$ were female, compared to $35.7 \%$ of male respondents.

From the responses, $70 \%$ indicated that work-life balance was a reason for choosing dentistry, with $45 \%$ of these responses from females. This is potentially due to flexible working hours, especially with childcare commitments. Furthermore, most respondents (72\%) felt that men and women are equally likely to succeed within the dental workforce. With regards to career success, $41 \%$ of respondents felt that men have an advantage over women in the dental workforce, primarily due to career breaks taken by women. The authors acknowledge that professional training pathways are traditionally structured around full-time male dentists, and therefore can be challenging for females with additional childcare responsibilities.

In terms of specialisation, more females select posts within paediatrics, orthodontics, and oral surgery. Thus, it is a pragmatic suggestion that more females will begin occupying senior positions that were traditionally male dominated as they specialise. Interestingly, $15.3 \%$ of female undergraduate students responded that they would like to specialise, compared to $100 \%$ of female DCTs. However, females are twice as likely to want to work part-time 15 years post-qualification compared to males. Further studies confirm that this is a general trend reflected amongst medical professionals.

The authors acknowledge the low response rate of DCTs in comparison to undergraduates, and that the cohort responses may not be indicative of the responses for students and DCTs nationally. Furthermore, respondents may interpret questions differently, which therefore will affect overall results. Further national research would allow for a greater knowledge on career aspirations of dentists to be ascertained, and therefore would help to facilitate an environment conducive towards female success within the dental workforce. A rich diversity of dental practitioners is vital as the profession continues to evolve.

Maryam Butt

Fourth Year Undergraduate Dental Student, King's College London, UK
Author Q\&A: Sadia Khan ${ }^{1}$ and

Sophia Ibrahim ${ }^{2}$

'Dental Core Trainee, Birmingham Dental Hospital: ${ }^{2}$ General Dental Practitioner

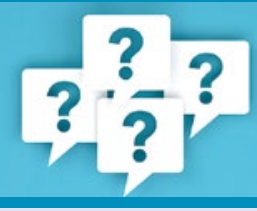

Why did you decide to undertake this study?

Anecdotally we saw a common trend that a large number of dentists graduating were females. We understood that this highlights the importance of females within the dental field and the increasing importance of their contributions. Therefore, we wanted to investigate the different career pathways taken post-graduation by gender, and more specifically to assess the long-term intentions of women in the field and aspirations of specialisation.

Did any of the results surprise you? Although some of the results were predictable, the surprising aspect was that although there are more females in the dental workforce, $41 \%$ of respondents felt men have an advantage over women in career success. The majority of undergraduates opted to work in practice upon graduation as a general dental practitioner (GDP). Eighty-three percent of dental core trainees (DCT) wanted to specialise. Of the DCTs, $100 \%$ of the females wanted to continue and specialise in comparison to $40 \%$ of males who were 'unsure' if they wanted to continue training and become a specialist.

What do you think the next steps should be considering your findings?

Further research is required ideally on a national level looking at a multicentre study gaining data from a variety of universities from the UK. These results then would represent a broad spread giving greater validity for a UK context. 